\title{
Rheumatologic rehabilitation: towards recommendations
}

\author{
S. Maddali Bongi, A. Del Rosso, M. Matucci Cerinic \\ Dipartimento di Biomedicina, Sezione di Reumatologia, centro DENOTHE, \\ Università degli Studi di Firenze, Italy
}

\begin{abstract}
SUMMARY
Rheumatic patients are highly complex and often affected by chronic diseases. Rehabilitation is generally needed for proper management of the underlying disease.

This article describes the characteristics of an effective rheumatologic rehabilitation, takes into account data published in international literature, suggests recommendations based on scientific evidence to develop a correct rehabilitation plan for rheumatic patients and proposes the basis to draw up guidelines in the field of rheumatologic rehabilitation.
\end{abstract}

Key words: Rheumatology, Rehabilitation, Physical exercise, Recommendations, Rheumatoid arthritis, Ankylosing spondylitis, Systemic sclerosis.

Reumatismo, 2014; 66 (3): 197-207

\section{INTRODUCTION}

A lthough etiology, severity and outcome of rheumatic diseases may differ, they all cause significant disability with remarkable disruptions in daily life and socio-economic and professional activities.

In Italy, the impact of chronic rheumatic diseases (chronic inflammatory arthritides, fibromyalgia syndrome, chronic low back pain, osteoarthritis, connective tissue disease, etc.) on work disability is significant and entails social security and healthcare costs in excess of 4 billion euro a year (1). Fifty percent of patients with rheumatoid arthritis (RA) present disability in daily household activities and $22.7 \%$ of them experience severe work limitations and may even have to quit their jobs (2).

According to the Rehabilitation Plan set out by the Italian Ministry of Health and published in 2011 (3), rheumatic patients can be defined as highly complex, because of their chronic diseases, often associated with severe systemic comorbidities and complications. His rehabilitation is, therefore, sometimes equally complex and needs to be conducted properly, as we have already underlined (4).
This article describes the requirements to be met for proper rheumatologic rehabilitation, takes into account data published in international literature, provides, according to the evidence of category A, B, C, D, recommendations for proper rehabilitation in patients with rheumatic diseases (Tab. I) and proposes the basis to draw up the first guidelines in the field of rheumatologic rehabilitation.

\section{CHARACTERISTICS OF RHEUMATOLOGIC REHABILITATION}

\section{Leading role of the rheumatologist}

As outlined in the Assessment of Spondyloarthirtis Society/European League Against Rheumatism (ASAS/EULAR) recommendations for the management of patients with ankylosing spondylitis (AS), the rheumatologist should be responsible for full management of patients (5) and their educational process and be regarded as their main reference person, who should also ensure adequate communication with all the members of the rehabilitation team. In particular, the rheumatologist has the following tasks in the rehabilitation process:
Corresponding author: Angela Del Rosso Dipartimento di Medicina Sperimentale e Clinica Sezione di Reumatologia Università degli Studi di Firenze Villa Monna Tessa

Viale G. Pieraccini, 18 - 50139 Firenze, Italy E-mail: angela.delrosso@fastwebnet.it 
Table I - Final recommendations.

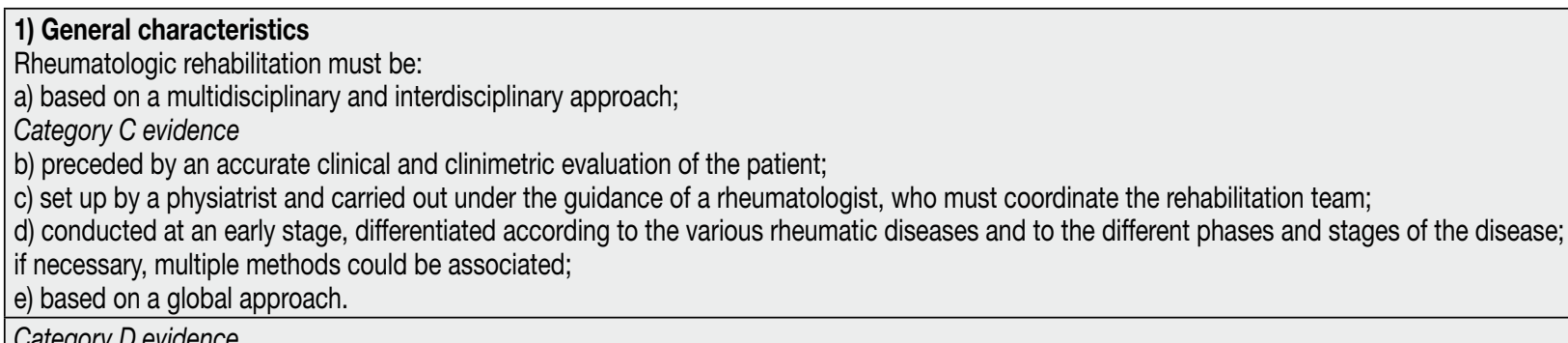

\section{Category $D$ evidence}

\section{2) Rheumatoid arthritis}

Full-body training, including aerobic exercises combined with muscle strengthening exercises, in patients with RA, is safe and recommended, and improves strength and physical function. It is recommended especially during the stable phase.

Full-body low-intensity exercises are more beneficial than high-intensity exercises in improving swelling, joint function and muscle strength.

Category A evidence

Joint protection programs in early RA and in severe and moderate RA improve pain and maintain function.

Category $B$ evidence

Balneotherapy and hydrotherapy are useful to relieve RA symptoms.

Category C Evidence

\section{3) Ankylosing spondylitis}

Home exercises are effective and rehabilitation with supervised exercises, both water- and land-based, individual or in groups, is preferable because it is more effective than home exercises.

Category A evidence

The combination of exercises and hydrotherapy followed by group exercise offers additional benefits compared with group exercises only. Category C evidence

\section{4) Systemic lupus erythematosus}

A careful, low- and moderate-intensity physical activity improves cardiovascular fitness, tolerance, exercise resistance and fatigue.

Category $B$ evidence

Hand physiotherapy and splints are useful in the Jaccoud's syndrome.

Category $D$ evidence

\section{5) Polymyositis and dermatomyositis}

Both in stable and active disease, aerobic and resistance exercises (from low to high intensity), performed with caution, improve function and muscle strength without significantly increasing disease activity or signs of inflammation.

\section{Category B evidence}

\section{6) Systemic sclerosis}

Self-administered home stretching and mobilization exercises improve hands and face functionality.

Category C evidence

Integrated rehabilitation protocols for hands and face improve local and global disability with persistent beneficial effects over time at the local level. Category A evidence

Aerobic and muscle strengthening exercises improve aerobic capacity and muscle strength.

Category $\mathrm{C}$ evidence

7) Fibromyalgia syndrome

Aerobic and stretching exercises, and muscle strengthening exercises, are effective to improve physical function and relieve symptoms.

Category A evidence

Hydrotherapy reduces pain and the number of tender points and improves the health status.

Category $A$ evidence

Mind-body therapies (Qi Gong, Tai Chi, Resseguier Method) reduce pain, tenderness and disability.

Category e Evidence

\section{8) Osteoarthritis}

\section{a) Hand $\mathrm{OA}$}

Joint protection, mobilization, strengthening exercises and heat are recommended.

Category $A$ evidence

b) OA of first MCP splint

Orthoses are recommended.

Category A evidence

c) Hip and knee $O A$

Aerobic exercises, muscle strengthening and joint mobilization exercises, hydrotherapy (for hip) are recommended.

Category A Evidence

RA, rheumatoid arthritis; OA, osteoarthritis; MCP, metacarpophalangeal joints. 
1) propose the rehabilitation plan to the patient, who must be prepared and guided by a physiatrist, who in Italy is responsible for the individual rehabilitation plan;

2) communicate a proper diagnosis to the rehabilitation team and define the presence and severity of extra-articular manifestations of the disease and other potential concomitant conditions, which may influence the rehabilitation process;

3 ) treat the underlying rheumatic disease with an adequate pharmacological treatment so as to allow for adequate rehabilitation to take place, monitor patient compliance and evaluate results at the end of the rehabilitation process and at follow-up with the rehabilitation team (6);

4) coordinate the rehabilitative team.

\section{A multidisciplinary and interdisciplinary approach}

A rehabilitation team should include different rehabilitation specialists, each with a specific role, such as a physical therapist, a rehabilitation nurse, an occupational therapist, a psychologist. This setup leads to greater clinical efficacy and reduction of rehabilitation costs $(7,8)$.

\section{Importance of early rehabilitation}

In rheumatology, rehabilitation and medical therapy should be initiated as soon as possible. Not only does this make the rehabilitation process more effective on pain and joint inflammation, but also on the evolution of the disease, because it may prevent joint alterations and associated disability, whereas at an advanced stage it may only reduce activity limitations and prevent further joint damage (9-11).

\section{Personalization and differentiation of the rehabilitation process}

Initially the rehabilitation program should include treatments targeted to the main joint alterations with the aim of relieving pain and preventing joint damage and deformity in the most affected areas. Afterwards it should also include a comprehensive rehabilitation plan to improve posture, muscle strength and the general health status of the patient.
The rehabilitation processes should be differentiated and personalized according to the various rheumatic diseases and their stages (12), as indicated by some British (13), French (14), and Canadian (15) scientific societies in relation to RA.

Also exercise intensity should be adequately planned on the basis of the maximum heart rate (MHR), when each individual rehabilitation plan is designed. Exercise intensity may be low (40-54\% MHR), moderate (55-69\% MHR) or high ( $\geq 70 \%$ MHR) depending on the patient overall health status, the rheumatic disease and its comorbidities. Also the type of exercise (static or dynamic) and the number of repeats, the duration and the frequency of the workout sessions, and the total duration of the rehabilitation process should be personalized according to the needs and the problems of each individual patient.

Both segmental (16-18) and global (19) methods should be combined in particular parts of the body and in different disease stages so as to achieve specific purposes, as demonstrated in the course of systemic sclerosis (SSc).

\section{A comprehensive rehabilitation approach} The musculoskeletal system should be treated in its entirety in order to avoid any worsening of impairments in other sites and prevent secondary damage due to gestural and postural adjustments.

A careful clinical and clinimetric evaluation of the patient by the rheumatologist and the rehabilitation team on the basis of anthropometric measurements, scales and questionnaires is required at both local (in affected joints) and global level.

Rehabilitation activities should cover all the requirements of the patient in the individual rehabilitation plan (20), which should be personalized and focus on both his/her physical situation and psychological and social needs.

\section{Central role of the patient in the rehabili- tation process}

According to the International Classification of Functioning, Disability and Health (ICF) (21), functioning and disability 
should be viewed as the result of complex interactions between the health condition of the individual patient and environmental and personal factors.

The picture resulting from this combination of factors and implications reflects the patient in his or her world. Since the individual rehabilitation plan is based on the ICF, the individual patient should play a central and active role in the rehabilitation treatment.

The patient may also actively participate in his/her global treatment by adding mindbody therapies (22-24), which can enhance perception and body awareness, thus leading him/her to identify postural and functional alterations and undertake readjustments of altered body patterns.

\section{Continuity of treatment}

Continuity of treatment is fundamental. Given the chronic nature of most rheumatic diseases, a rapid reduction in the efficacy of any rehabilitation method after its discontinuation is demonstrated.

Therefore, we recommend adopting the following measures:

1) repeated cycles of rehabilitation therapy, alternating individual sessions and group courses under the supervision of a physical therapist;

2) home exercises and educational programs administered to the patient;

3 ) regular physical activity in keeping with the phase and the state of the disease and any potential involvement of internal organs (25).

\section{Absence of pain}

Every rehabilitation treatment should always be performed when the patient has no pain due to inflamed joints, otherwise it may lead to serious structural damages. Moreover, as recently outlined, pain causes neuronal sensitization at both spinal and supra-spinal levels, which, in turn, may make articular or extra-articular musculoskeletal pain become chronic (26). For this reason, manual therapies are preferable to the use of equipment, which is less sensitive than the hands of a skilled physical therapist (6).
EVIDENCE-BASED DATA FOR RHEUMATOLOGIC REHABILITATION

\section{Rheumatoid arthritis}

Rehabilitation is critical in the management of RA and should be differentiated according to the stage of the disease, especially for the hands. It may include different rehabilitation methods.

Rehabilitation and non-pharmacological management are not considered in the recommendations drawn up by EULAR for the diagnosis and treatment of RA. The American College of Rheumatology (ACR) recommends joint protection, home exercises, and programs based on dynamic and aerobic exercises (11), according to specific programs (27).

The recommendations of the Brazilian society of rheumatology encourage physical therapy, rehabilitation and occupational therapy, since the initial evaluations (28). In early arthritis, dynamic exercises, occupational therapy and hydrotherapy are recommended in addition to medical therapy (29).

According to Cochrane reviews and randomized controlled trials in patients with RA, full-body exercises combining aerobic training with muscle strengthening exercises are safe and recommended (30) and improve strength and physical function, although clear effects on the activity of the disease have not been identified. In early RA (9) and in moderate and severe RA, joint protection programs relieve pain and maintain function (31). In RA, balneotherapy $(32,33)$ (baths in thermal mineral waters at a temperature around $34^{\circ} \mathrm{C}$ included or not in a spa therapy with physiotherapy) and hydrotherapy (supervised exercises in warm water) (34) are sometimes used. However, none of them has yielded any evidence to support this as strong recommendation.

As to land-based exercises, the above-mentioned guidelines (14-16) recommend the following:

- In RA, especially in the early phases of the disease, land-based exercises, performed even at high intensity and for a long 
time, produce benefits without increasing radiographic damage and exacerbating the disease. They can be continued in the active phase. However, when performing dynamic exercises, caution is always advisable $(35,36)$.

- Aerobic exercises at moderate or high intensity are recommended as routine practice in patients with stable RA (and are also useful for co-morbidities).

- In active RA and in RA with severe joint damage, low intensity exercises are more recommended.

- Full-body low-intensity rather than highintensity exercises offer more benefits in terms of pain relief (Grade A evidence in randomized clinical trials) and clinically detectable benefits in terms of less swelling and better joint function and muscle strength.

On the basis of published evidence, the most recommended rehabilitation techniques are as follows:

- Joint exercises (hands):

1) Acute phases and damaged joints: isometric and stretching exercises to maintain muscle tone and trophism and prevent the onset of altered posture, potentially causing joint deformity.

2) Stable phase:

a) cautious passive mobilization to avoid joint stiffness and maintain or restore joint mobility;

b) active mobilization to maintain and increase joint mobility.

3) Remission phase: active mobilization: to strengthen, stretch and balance the musculoskeletal system with minimal load on the joints.

\section{- Full-body exercises}

1) Sub-acute phase

a) hydrotherapy (mobilization exercises for upper and lower limbs, muscle strengthening exercises, stretching and muscle relaxation exercises);

b) balneotherapy;

c) land-based low-intensity exercises;

d) mind-body therapies (Tai Chi, Qi Gong, Yoga, Mindfulness Meditation).

2) Stable phase and remission phase: landbased aerobic exercises at moderate/high intensity.

\section{Ankylosing spondylitis}

In ankylosing spondylitis, rehabilitation is as important as pharmacological therapy, although it is not possible to define specific methods to be adopted for therapeutic exercise and rehabilitation. However, in order to be effective, these exercises should be performed with consistency and continuity, and, due to the significant functional and structural changes that AS causes on posture, they should involve the entire body and not only few joints.

The 2008 Cochrane review (10) concludes that in AS any kind of exercise is more beneficial than no intervention in terms of pain relief and improvement of physical function, spinal mobility and patient global assessment. Supervised exercise is better than non-supervised exercise and group therapy is better than individual therapy and home exercise.

In the updated EULAR recommendations for the treatment of AS, physical exercises are mentioned among non-pharmacological treatments, together with patient education. These recommendations, based on a systematic literature review (37), confirm the conclusions of the Cochrane review and indicate that home exercise are effective, but both water- and land-based supervised exercises, either individual or in groups, should be preferred, because they are even more beneficial than home exercises (38). Different kinds of exercises (supervised group exercises, home exercises, full-body postural rehabilitation) have positive effects on spinal function, disease activity, pain and mobility $(10,37)$.

As to hydrotherapy, both the Cochrane review and EULAR recommendations indicate that a combination of exercises with hydrotherapy, followed by group exercises, are even more beneficial than group therapy alone $(10,37)$.

The goals of rehabilitation in AS differ according to the phase and the stage of disease. In particular, the rehabilitation treatment, associated with an appropriate pharmacological therapy, should be aimed to achieve the following goals:

1) in the acute phase, relief of pain and painful muscle spasms that cause second- 
ary damage due to gestural and postural adjustments;

2) in the post-acute phase, recovery of joint mobility, improvement of muscle tonetrophism and reduction of progressive rigidity, that causes functional and respiratory limitations;

3 ) in the early stage, mainly preventive purposes;

4) in the advanced stage, primarily rehabilitation purposes.

On the basis of published evidence, the most recommended rehabilitation techniques are as follows:

- Acute and sub-acute phase:

1) hydrotherapy (including breathing exercises);

2) balneotherapy;

3) low-intensity exercises in the gym or at home (including postural and breathing exercises).

- Stable phase and remission:

1) hydrotherapy (including breathing exercises and swimming);

2) exercises in the gym or at home with moderate/high intensity (including breathing exercises).

\section{Systemic connective tissue diseases}

In this group of diseases, which cause severe systemic involvement, although rehabilitation is considered important and has been evaluated in a few studies, no guidelines, nor specific recommendations are available.

\section{Systemic lupus erythematosus}

A controlled, low- or moderate-intensity, physical activity can improve cardiovascular fitness, which is impaired in patients with systemic lupus erythematosus, who are deconditioned and with reduced exercise capacity, by improving heart rate (39), aerobic capacity, tolerance and resistance to exercise $(40,41)$. Moreover, it can improve fatigue (42) and physical function in patients with low disease activity, without exacerbating it (43). However the results of these studies should be taken with caution, because they were performed on small groups of patients in remission. It is recommended to prescribe and perform exer- cises with care to avoid worsening disease symptoms.

A specific hand kinesitherapy and splints should be used in patients with Jaccoud's syndrome, in order to avoid that hand deformities become chronic (6).

On the basis of published evidence, the most recommended rehabilitation techniques are as follows:

1) specific kinesitherapy for the hands;

2) aerobic exercises at low/moderate intensity.

\section{Polymyositis and dermatomyositis}

In these diseases, exercise aims to prevent disuse atrophy of muscle fibers that are not involved by the disease process, and muscle retraction, which may further worsen disability due to the loss of muscle fibers.

In the course of polymyositis (PM), various types of exercises, also at high intensity, can improve function and muscle strength without significantly worsening disease activity or inflammation in muscle biopsies $(45,46)$. These results contradict previous studies which indicated that exercise, especially with eccentric muscle contractions, may worsen the disease damages, causing further damage and inflammation in muscles $(47,48)$.

Although larger studies are needed to prove the safety and the benefits of various types of exercises, active exercises, if adapted to the disease activity and the degree of disability, can be included in the rehabilitation of patients with PM at all disease stages (49), paying attention not to cause fatigue and pain.

On the basis of published evidences, the most recommended rehabilitation techniques in active or stable disease are as follows:

1) aerobic exercises (from low to high intensity);

2) exercises for resistance training (from low to high intensity).

\section{Systemic sclerosis}

Although in SSc, rehabilitation programs and physiotherapy are recommended to prevent and reduce disability, due to skin and musculoskeletal involvement, only a 
few studies on this topic have been published (50).

For the face, which is involved in the disease process from the early phases, selfadministered stretching exercises for the mimic muscles and exercises to reduce microstomia improve mouth opening (51). A protocol combining connective tissue massage, Kabat technique, physiokinesitherapy and home exercises can improve facial skin induration, mouth opening and functionality more than home exercises (16).

For the hands, exercises including stretching and mobilization of the fingers (sometimes associated with local application of paraffin) improve hand function and mobility $(52,53)$. In patients with flexion contractures of the hands, a protocol combining connective tissue massage, McMennell manipulation and home exercises improve hand function and fist closure and also general disability more than home exercises alone (18).

In patients with early SSc and edematous hands, manual lymphatic drainage massage improves hand edema and function and relieves hand pain (17).

Combined protocols, which are specific to SSc and differentiated according to the needs of patients, including global and segmental techniques, improve both the overall quality of life and hand and face disability $(19,54)$. Aerobic exercises (55), associated with resistance exercises (56), improve aerobic capacity and muscle strength in patients without pulmonary involvement. However, these results should be considered with caution, because they refer to exercises performed by small groups of patients in remission.

On the basis of published evidence, the most recommended rehabilitation techniques are as follows:

- Hands and face:

1) self-administered home exercises, including stretching and mobilization;

2) combined rehabilitation protocols performed with additional segmental techniques;

- Full-body exercises:

1) combined rehabilitation protocols in- cluding both segmental and full-body techniques;

2) aerobic and muscle strengthening exercises.

\section{Fibromyalgia syndrome}

Rehabilitation is considered useful and is included in the multidisciplinary treatment of fibromyalgia syndrome (FMS) proposed by the American Pain Society and the Association of the Scientific Medical Societies of Germany (57), which strongly recommend aerobic exercise as part of a multidisciplinary approach to this disease. EULAR assigns a high level of recommendation to the mind-body therapies, such as cognitive behavioral therapy (58).

The 2007 Cochrane Review comparing aerobic exercises with muscle strengthening and stretching exercises reported strong evidence that controlled training with aerobic exercises has beneficial effects on physical capacity and FMS symptoms. No conclusions may be drawn for other types of exercise (59), however data from the literature (with a Grade A evidence) show that strengthening exercises in FMS improves pain, depression and disability (60), quality of life (61), and muscle strength $(62,63)$.

However some basic rules need to be followed to avoid that physical activity may cause symptom exacerbation, particularly pain, and a high number of drop-outs from exercise protocols (as reported), namely increase progressively intensity of workout, monitor the patient frequently and, in case of adverse events, reduce intensity of exercise, until they disappear.

In 2008, the Ottawa Panel published evidence-based recommendations about aerobic (64) and muscle strengthening exercises (65) for FMS patients.

Moreover hydrotherapy, balneotherapy and spa therapy reduced pain and the number of tender points and improved the health status of patients, although for a short time (66). A subsequent article showed, however, the persistence (after 5 months of follow-up) of pain reduction after rehabilitation with hydrotherapy (67).

Mind-body therapies, which act in an integrated way on both the mind and the body, 
are an excellent rehabilitation approach for FMS patients and are particularly suited to their complex psychological and functional alterations. Some scientific evidences also show promising results from other methods, such as Qi Gong $(68,69)$, Tai Chi $(70)$, and Resseguier Method (71).

On the basis of published evidence, the most recommended rehabilitation techniques are as follows:

1) aerobic, muscle strengthening and stretching exercises;

2) hydrotherapy and swimming;

3) mind-body therapies (Qi Gong, Tai Chi, Resseguier Method).

\section{Osteoarthritis}

Exercise and rehabilitation are recommended and included in the treatment of osteoarthritis (OA), despite significant scientific evidence is lacking.

For hand OA, EULAR recommends joint protection programs, mobilization and strengthening exercises and local therapy with heat application and ultrasound and, in the case of trapeziometacarpal (TMC) $\mathrm{OA}$, the use of splints and orthoses (72) (category D evidence). After this publication, two randomized controlled trials demonstrated, in TMC OA, the superiority of splints compared with the conventional treatment in terms of pain relief, ability, strength and hand function $(73,74)$ (category A evidence).

Exercise is included in EULAR recommendations and accepted by the Italian Society of Rheumatology for the non-pharmacological treatment of hip $(75,76)$ and knee OA $(77,78)$. These recommendations did not indicate conclusive evidence that exercise is useful in hip OA, but prescribe exercise in order to improve pain and function in patients with knee OA.

An update of these recommendations, which were jointly developed by EULAR and Osteoarthritis Research Society International (OARSI), encourage patients with symptomatic hip and knee OA to see a physical therapist to perform exercises for pain relief and function improvement (category D evidence). These patients should also be advised to perform aerobic, mus- cle strengthening and joint mobilization exercises. For patients with symptomatic hip OA, hydrotherapy can be also effective (category A evidence) (79).

On the basis of published evidences, the most recommended rehabilitation techniques are as follows:

1) hand OA: joint protection, mobilization and strengthening exercises, heat, splint orthoses (TMC OA);

2) hip and knee OA: aerobic, muscle strengthening and joint mobilization exercises; hydrotherapy (only for hip OA).

Conflict of interests: the authors declare no potential conflict of interests.

\section{REFERENCES}

1. Ridolfi A. Ricerca compiuta dall'Osservatorio Sanità e Salute presentata il 5/12/2008 in occasione del Convegno Malattie Reumatiche: disabilità, impatto sul lavoro e costi sociali. Available from: http://www.anmar-italia.it/

2. Associazione Nazionale Malati Reumatici (ANMAR), Società Italiana di Reumatologia (SIR), Censis. Un percorso a ostacoli. Primo rapporto sociale sull'artrite reumatoide Roma, ottobre 2008. Available from: http:// www.reumatologia.it/obj/file/RapportoSociale.pdf

3. Ministero della Salute Italiana. Piano di indirizzo per la riabilitazione. In: G.U. no. 50, 02/03/2011, Suppl. Ord. no. 60: 164-183.

4. Maddali Bongi S, Matucci Cerinic M. Rheumatologic rehabilitation: the great expectation for rheumatic patients. Reumatismo. 2012; 64: 1-6.

5. Braun J, van den Berg R, Baraliakos X, Boehm H, Burgos-Vargas R, Collantes-Estevez E, et al. 2010 update of the ASAS/EULAR recommendations for the management of ankylosing spondylitis. Ann Rheum Dis. 2011; 70: 896-904

6. Maddali Bongi S. L'approccio riabilitativo al malato reumatico. In: Maddali Bongi S, ed. Riabilitazione reumatologica: approccio multidisciplinare. Milano: EDRA; 2007.

7. van den Hout WB, Tijhuis GJ, Hazes JM, Breedveld FC, Vliet Vlieland TP. Cost effectiveness and cost utility analysis of multidisciplinary care in patients with rheumatoid arthritis: a randomised comparison of clinical nurse specialist care, inpatient team care, and day patient team care. Ann Rheum Dis. 2003; 62: 308-15.

8. Häuser W, Bernardy K, Arnold B, Offenbäch- 
er M, Schiltenwolf M. Efficacy of multicomponent treatment in fibromyalgia syndrome: a meta-analysis of randomized controlled clinical trials. Arthritis Rheum. 2009; 61: 216-24.

9. Steultjens EM, Dekker J, Bouter LM, van Schaardenburg D, van Kuyk MA, van den Ende $\mathrm{CH}$. Occupational therapy for rheumatoid arthritis. Cochrane Database Syst Rev. 2004; (1): CD003114.

10. Dagfinrud H, Kvien TK, Hagen KB. Physiotherapy interventions for ankylosing spondylitis. Cochrane Database Syst Rev. 2008; (1): CD002822.

11. American College of Rheumatology Subcommittee on Rheumatoid Arthritis Guidelines. Guidelines for the management of rheumatoid arthritis: 2002 Update. Arthritis Rheum. 2002; 46: 328-46.

12. Maddali Bongi S, Del Rosso A. [How to prescribe physical exercise in rheumatology]. Reumatismo 2010; 62: 4-11 [in Italian].

13. NICE National Institute for health and Clinical Excellence. Rheumatoid Arthritis. National clinical guideline for management and treatment in adults. NICE Clinical Guideline; 2009.

14. Forestier R, André-Vert J, Guillez P, Coudeyre E, Lefevre-Colau MM, Combe B, et al. Nondrug treatment (excluding surgery) in rheumatoid arthritis: clinical practice guidelines. Joint Bone Spine. 2009; 76: 691-8.

15. Ottawa Panel evidence-based clinical practice guidelines for therapeutic exercises in the management of rheumatoid arthritis in adults. Phys Ther. 2004; 84: 934-72.

16. Maddali-Bongi S, Landi G, Galluccio F, Del Rosso A, Miniati I, Conforti ML, et al. The rehabilitation of facial involvement in systemic sclerosis: efficacy of the combination of connective tissue massage, Kabat's technique and kinesitherapy: a randomized controlled trial. Rheumatol Int. 2011; 31: 895-901.

17. Maddali Bongi S, Del Rosso A, Passalacqua M, Miccio S, Mattucci Cerinic M. Manual lymph drainage improves upper limb oedema and hand function in patients with systemic sclerosis (SSc) in oedematous phase. Arthritis Care Res. 2011; 63: 1134-41.

18. Maddali Bongi S, Del Rosso A, Galluccio F, Sigismondi F, Miniati I, Conforti ML, et al. Efficacy of connective tissue massage and Mc Mennell joint manipulation in the rehabilitative treatment of the hands in systemic sclerosis. Clin Rheumatol. 2009; 28: 1167-73.

19. Maddali Bongi S, Del Rosso A, Galluccio F, Tai G, Sigismondi F, Passalacqua M, et al. Efficacy of a tailored rehabilitation program for systemic sclerosis. Clin Exp Rheumatol. 2009; 27: 44-50.

20. Ministero della Salute Italiana. Linee-guida del Ministro della Sanità per le attività di riabilitazione. In: G.U. no. 124, 30/051998.
21. World Health Organization. International Classification of Functioning, Disability and Health (ICF). http://www.who.int/classifications/icf/en/ Accessed: March 13, 2014.

22. Wang C. Tai chi and rheumatic diseases. Rheum Dis Clin North Am. 2011; 37: 19-32.

23. Lee MS, Pittler MH, Ernst E. Internal qigong for pain conditions: a systematic review. J Pain 2009; 10: 1121-7.

24. Cramer H, Lauche R, Langhorst J, Dobos G. Yoga for rheumatic diseases: a systematic review. Rheumatology (Oxford). 2013; 52: 2025-30.

25. van den Berg MH, de Boer IG, le Cessie S, Breedveld FC, Vliet Vlieland TP. Most people with rheumatoid arthritis undertake leisuretime physical activity in the Netherlands: an observational study. Aust J Physiother. 2007; 5: 113-8.

26. Lee YC, Nassikas NJ, Clauw DJ. The role of the central nervous system in the generation and maintenance of chronic pain in rheumatoid arthritis, osteoarthritis and fibromyalgia. Arthritis Res Ther. 2011; 13: 211.

27. [No authors listed]. Work group recommendations: 2002 Exercise and Physical Activity Conference, St. Louis, Missouri. Session V: evidence of benefit of exercise and physical activity in arthritis. Arthritis Rheum. 2003; 49: 453-4.

28. da Mota LM, Cruz BA, Brenol CV, Pereira IA, Rezende-Fronza LS, Bertolo MB, et al. 2012 Brazilian Society of Rheumatology Consensus for the treatment of rheumatoid arthritis. Rev Bras Reumatol. 2012; 5: 152-74.

29. Combe B, Landewe R, Lukas C, Bolosiu HD, Breedveld F, Dougados M. Non-pharmaceutical interventions such as dynamic exercises, occupational therapy, and hydrotherapy can be applied as adjuncts to pharmaceutical interventions in patients with early arthritis. Ann Rheum Dis 2007; 66: 34-45.

30. Hurkmans E, van der Giesen FJ, Vliet Vlieland TP, Schoones J, Van den Ende EC. Dynamic exercise programs (aerobic capacity and/ or muscle strength training) in patients with rheumatoid arthritis. Cochrane Database Syst Rev. 2009; (4): CD006853.

31. Hammond A, Bryan J, Hardy A Effects of a modular behavioural arthritis education programme: a pragmatic parallel-group randomized controlled trial. Rheumatology 2008; 47: 1712-8.

32. Verhagen AP, Bierma-Zeinstra SM, Cardoso JR, de Bie RA, Boers M, de Vet HC. Balneotherapy for rheumatoid arthritis. Cochrane Database Syst Rev. 2003; (4): CD000518.

33. Karagulle MZ, Karagulle M. [Balneotherapy and spa therapy of rheumatic diseases in Turkey: a systematic review]. Forsch Komplementarmed Klass Naturheilkd 2004; 11: 33-41 [Article in German]. 
34. Eversden L, Maggs F, Nightingale P, Jobanputra P. A pragmatic randomised controlled trial of hydrotherapy and land exercises on overall well being and quality of life in rheumatoid arthritis. BMC Musculoskelet Disord. 2007; 8: 23.

35. Gaudin P, Leguen-Guegan S, Allenet B, Baillet A, Grange L, Juvin R. Is dynamic exercise beneficial in patients with Rheumatoid Arthritis? Joint Bone Spine. 2008; 75: 11-7.

36. Oldfield V, Felson DF. Exercise therapy and orthotic devices in rheumatoid arthritis: evidence-based review. Curr Opin Rheumatol. 2008; 20: 353-9.

37. van den Berg R, Baraliakos X, Braun J, van der Heijde D. First update of the current evidence for the management of ankylosing spondylitis with non-pharmacological treatment and nonbiologic drugs: a systematic literature review for the ASAS/EULAR management recommendations in ankylosing spondylitis. Rheumatology (Oxford). 2012; 51: 1388-96.

38. Braun J, van den Berg R, Baraliakos X, Boe$\mathrm{hm} \mathrm{H}$, Burgos-Vargas R, Collantes-Estevez E, et al. 2010 update of the ASAS/EULAR recommendations for the management of ankylosing spondylitis. Ann Rheum Dis. 2011; 70: 896-904.

39. Miossi R, Benatti FB, Lúciade de Sá Pinto A, Lima FR, Borba EF, Prado DM, et al. Using exercise training to counterbalance chronotropic incompetence and delayed heart rate recovery in systemic lupus erythematosus: a randomized trial. Arthritis Care Res (Hoboken). 2012; 64: 1159-66.

40. Robb-Nicholson L, Daltroy L, Eaton H, Gall V, Wright E, Hartley LH, et al. Effects of aerobic conditioning in lupus fatigue: a pilot study. Br J Rheumatol. 1989; 28: 500-5.

41. Ramsey-Goldman R, Schilling EM, Dunlop D, Langman C, Greenland P, Thomas RJ, et al. A pilot study on the effects of exercise in patients with systemic lupus erythematosus. Arthritis Care Res. 2000; 13: 262-9.

42. Tench C, McCarthy J, McCurdle I, White P, D'Cruz DP. Fatigue in systemic lupus erythematosus: a randomized controlled trial of exercise. Rheumatology (Oxford). 2003; 42: 1050-4.

43. Strömbeck B, Jacobsson LT. The role of exercise in the rehabilitation of patients with systemic lupus erythematosus and patients with primary Sjögren's syndrome. Curr Opin Rheumatol. 2007; 19: 197-203.

44. Barnes JN, Tanaka H. Cardiovascular benefits of habitual exercise in systemic lupus erythematosus: a review. Phys Sportsmed. 2012; 40: 43-8.

45. Alexanderson H, Dastmalchi M, EsbjörnssonLiljedahl M, Opava CH, Lundberg IE. Benefits of intensive resistance training in patients with chronic polymyositis or dermatomyosi- tis. Arthritis Rheum. 2007 15; 57: 768-77.

46. Alexanderson H. Exercise in inflammatory myopathies, including inclusion body myositis. Curr Rheumatol Rep. 2012; 14: 244-51.

47. Fielding RA, Manfredi TJ, Ding W, Fiatarone MA, Evans WJ, Cannon JG. Acute phase response in exercise. III. Neutrophil and IL-1 beta accumulation in skeletal muscle. Am J Physiol. 1993; 265: R166-72.

48. Sorichter S, Koller A, Haid C, Wicke K, Judmaier W, Werner $\mathrm{P}$, et al. Light concentric exercise and heavy eccentric muscle loading: effects on CK, MRI and markers of inflammation. Int J Sports Med. 1995; 16: 288-92.

49. Lawson Mahowald M. The benefits and limitations of a physical training program in patients with inflammatory myositis. Curr Rheumatol Rep. 2001; 3: 317-24.

50. Poole JL. Musculoskeletal rehabilitation in the person with scleroderma. Curr Opin Rheumatol. 2010; 22: 205-12.

51. Pizzo G Scardina GA, Messina P. Effects of a non surgical exercise program on the decreased mouth opening in patients with systemic scleroderma. Clin Oral Investig. 2003; 7: $175-8$.

52. Mugii N, Hasegawa M, Matsushita T, et al. The efficacy of self-administered stretching for finger joint motion in Japanese patients with systemic sclerosis. J Rheumatol. 2006; 33: 1586-92.

53. Sandqvist G, Akesson A, Eklund M. Evaluation of paraffin bath treatment in patients with systemic sclerosis. Disabil Rehabil. 2004; 26: 981-7.

54. Antonioli CM, Bua G, Frigè A, Prandini K, Radici S, Scarsi M, et al. An individualized rehabilitation program in patients with systemic sclerosis may improve quality of life and hand mobility. Clin Rheumatol 2009; 28: 159-65.

55. Oliveira NC, dos Santos Sabbag LM, de Sá Pinto AL, Aerobic exercise is safe and effective in systemic sclerosis. Int J Sports Med. 2009; 30: 728-32.

56. Pinto AL, Oliveira NC, Gualano B, Christmann RB. Efficacy and safety of concurrent training in systemic sclerosis. J Strength Cond Res. 2011; 25: 1423-8.

57. Häuser W, Arnold B, Eich W, Felde E, Flügge $\mathrm{C}$, Henningsen $\mathrm{P}$, et al. Management of fibromyalgia syndrome - an interdisciplinary evidence-based guideline. Ger Med Sci. 2008; 6: Doc14.

58. Carville SF, Arendt-Nielsen S, Bliddal H, Blotman F, Branco JC, Buskila D, et al. EULAR evidence-based recommendations for the management of fibromyalgia syndrome. Ann Rheum Dis. 2008; 67: 536-41.

59. Busch AJ, Barber KA, Overend TJ, Peloso PM, Schachter CL. Exercise for treating fibromyalgia syndrome. Cochrane Database Syst Rev. 2007; (4): CD003786. 
60. Häkkinen A, Häkkinen K, Hannonen P, Alen M. Strength training induced adaptations in neuromuscular function of premenopausal women with fibromyalgia: comparison with healthy women. Ann Rheum Dis. 2001; 60: 21-6.

61. Jones KD, Burckhardt CS, Clark SR, Bennett RM, Potempa KM. A randomized controlled trial of muscle strengthening versus flexibility training in fibromyalgia. J Rheumatol. 2002; 29: 1041-8.

62. Valkeinen $\mathrm{H}$, Alen M, Hannonen P, Häkkinen A, Airaksinen O, Häkkinen K. Changes in knee extension and flexion force, EMG and functional capacity during strength training in older females with fibromyalgia and healthy controls. Rheumatology (Oxford). 2004; 43: 225-8.

63. Kingsley JD, Panton LB, Toole T, Sirithienthad P, Mathis R, McMillan V. The effects of a 12-week strength-training program on strength and functionality in women with fibromyalgia. Arch Phys Med Rehabil. 2005; 86: 1713-21.

64. Brosseau L, Wells GA, Tugwell P, Egan M, Wilson KG, Dubouloz CJ, et al. Ottawa Panel evidence-based clinical practice guidelines for aerobic fitness exercises in the management of fibromyalgia: part 1. Phys Ther. 2008; 88: 857-71.

65. Brosseau L, Wells GA, Tugwell P, Egan M, Wilson KG, Dubouloz CJ, et al. Ottawa Panel evidence-based clinical practice guidelines for strengthening exercises in the management of fibromyalgia: part 2. Phys Ther. 2008; 88: 873-86.

66. McVeigh JG, McGaughey H, Hall M, Kane P. The effectiveness of hydrotherapy in the management of fibromyalgia syndrome: a systematic review. Rheumatol Int. 2008; 29: 119-30.

67. Evcik D, Yigit I, Pusak H, Kavuncu V. Effectiveness of aquatic therapy in the treatment of fibromyalgia syndrome: a randomized controlled open study. Rheumatol Int. 2008; 28: 885-90.

68. Haak T, Scott B. The effect of Qi gong on fibromyalgia (FMS): a controlled randomized study. Disabil Rehabil. 2008; 30: 625-33.

69. Maddali Bongi S, Del Rosso A, Di Felice C, Calà M, Giambalvo Dal Ben G. Rességuier method and Qi Gong sequentially integrated in patients with fibromyalgia syndrome. Clin Exp Rheumatol. 2012; 30: 51-8.

70. Wang C, Schmid CH, Rones R, Kalish R, Yinh J, Goldenberg DL, Lee Y, McAlindon T.
A randomized trial of tai chi for fibromyalgia. N Engl J Med. 2010; 363: 743-54.

71. Maddali Bongi S, Di Felice C, Del Rosso A, Galluccio F, Landi G, Tai G, Giambalvo Dal Ben G, Matucci Cerinic M. The efficacy of the Rességuier method in the treatment of fibromyalgia syndrome: a randomized controlled trial. Clin Exp Rheumatol. 2010; 28: S46-50.

72. Zhang W, Doherty M, Leeb BF, Alekseeva L, Arden NK, Bijlsma JW, et al. EULAR evidence based recommendations for the management of hand osteoarthritis: report of a Task Force of the EULAR Standing Committee for International Clinical Studies Including Therapeutics (ESCISIT). Ann Rheum Dis. 2007; 66: 377-88.

73. Rannou F, Dimet J, Boutron I, Baron G, Fayad F, Mace Y, et al. Splint for base-of-thumb osteoarthritis: a randomized trial. Ann Intern Med. 2009; 150: 661-9.

74. Gomes Carreira AC, Jones A, Natour J. Assessment of the effectiveness of a functional splint for osteoarthritis of the trapeziometacarpal joint on the dominant hand: a randomized controlled study. J Rehabil Med. 2010; 42: 469-74.

75. Zhang W, Doherty M, Arden N, Bannwarth B, Bijlsma J, Gunther KP, et al. EULAR evidence based recommendations for the management of hip osteoarthritis: report of a task force of the EULAR Standing Committee for International Clinical Studies Including Therapeutics (ESCISIT). Ann Rheum Dis. 2005; 64: 66981.

76. Punzi L, Doherty M, Zhang W, Cimmino MA, Carrabba M, Frizziero L. Italian consensus on EULAR recommendations 2005 for the management of hip osteoarthritis. Reumatismo. 2006; 58: 301-9.

77. Zhang W, Doherty M, Peat G, Bierma-Zeinstra MA, Arden NK, Bresnihan B, EULAR evidence-based recommendations for the diagnosis of knee osteoarthritis. Ann Rheum Dis. 2010; 69: 483-9.

78. Punzi L, Canesi B, Carrabba M, Cimmino MA, Frizziero L, Lapadula G. Italian consensus on Eular 2003 recommendations for the treatment of knee osteoarthritis. Reumatismo. 2004; 56: 190-201.

79. Zhang W, Moskowitz RW, Nuki G, Abramson $\mathrm{S}$, Altman RD, Arden N, et al. OARSI recommendations for the management of hip and knee osteoarthritis, Part II: OARSI evidencebased, expert consensus guidelines. Osteoarthritis Cartilage. 2008; 16: 137-62. 